\title{
Nesting strategy and the niche partitioning in two socially monogamous songbirds
}

\author{
Nao Ota ${ }^{1}$ \\ ${ }^{1}$ Max-Planck-Institut fur Ornithologie
}

November 17, 2021

\begin{abstract}
Niche partitioning is often vital for the coexistence of ecologically similar species under limited resources. Here I will report the nesting strategy of the two sympatric songbirds and the species differences, which have been overlooked in the past. Blue-capped and red-cheeked cordon-bleus are socially monogamous, biparental songbirds (family Estrildidae) that sympatrically inhabit East Africa. My field observation during their breeding season revealed that red-cheeked cordon-bleus build their nests near wasp nests more frequently than blue-capped cordon-bleus. Blue-capped cordon-bleus instead tended to take over weaver's old nest more often or use a broader range of nesting materials compared to red-cheeked cordon-bleus. These nesting strategies are already described in the literature as common behaviors in both species. However, the species differences of the adopting strategies have never been reported. While Estrildid finches are one of the best well-studied bird families of their behavior under the captive condition, my finding suggests that we still have limited knowledge of their wild behaviors and ecological plausibility, which is required to understand the functions and evolution.
\end{abstract}

\section{Introduction}

Niche partitioning has an important role in the coexistence of multiple species with similar ecology (Levine and HilleRisLambers 2009). It is rather natural that ecologically similar species use different resources such as foods (Hasui et al. 2009) and nest sites (Kosinski and Winiecki 2004, Vierling et al. 2009) depending on the availability in the shared habitat to avoid conflicts and competitions. Knowing strategies that animals adopt to coexist with other species is essential not only for understanding the biodiversity and ecosystems but also for elucidating factors that shape their behavior and cognitive functions.

Estrildid finches are one of the most well-studied songbird families regarding their behavior from its neural mechanisms to evolution (e.g., courtship song: Catchpole and Slater 2003, Soma and Garamszegi 2015; nest-building: Bailey et al. 2014, Guillette and Healy 2015, Hall et al. 2015), while we have limited knowledge of their wild behavior and the environmental conditions in many species. Blue-capped cordon-bleus (Uraeginthus cyanocephalus ) and red-cheeked cordon-bleus (Uraeginthus bengalus ) are socially monogamous, biparental Estrildid finches from Africa. Male blue-capped and red-cheeked cordon-bleus, as their names suggest, have blue caps and red cheeks, respectively (Fig. 1). Female blue-capped cordon-bleus have brighter blue plumage and pink beak than red-cheeked (Fig. 1). They are sister species and have similar life history and breeding behavior, and their habitat overlaps in East Africa (Goodwin 1982, Hockey et al. 2005, Billerman et al. 2020). Past literature generally mentioned the ecological and behavioral similarities between the two species and usually neglected the possibility of adopting different behavioral strategies to avoid conflicts in the shared habitat.

The nest building behavior of cordon-bleus is characteristic in several ways. They build their nest in trees mainly using grasses, but sometimes take over weaver (Ploceus spp. or Bubalornis spp.) old nests (Fig. $2 \mathrm{~b}, \mathrm{c}$ ). They often build a nest near wasp nests (Hymenoptera: Vespidae) to reduce the predation risk (Fig. 
2a, c, d; Goodwin 1982, Hockey et al. 2005, Beier and Tungbani 2006, Billerman et al. 2020). During my fieldwork in Tanzania, I observed that cordon-bleus used the same nesting strategies as previously reported (Fig. 2). The primary purpose of the expedition was to observe the multimodal courtship display of wild cordon-bleus (Ota 2020), but I could also observe nest-building behavior and the nests during the study (Fig. 2, Movie S1). When attempting to observe the courtship behavior of cordon-bleus, I usually focus on individuals holding a piece of nest materials on their beak since cordon-bleus perform courtship displays with holding them (Ota 2020). Cordon-bleus holding a piece of nest materials often carried them to their nests (Movie S1) rather than using them for courtship. In addition, I confirmed that two species of cordon-bleus actually inhabited and breed sympatrically at my field site (see results, Fig. 3), so I expected it would be an ideal opportunity to examine their nesting strategies and the species differences.

I hypothesized that the adopting nesting strategies and their frequency vary between two cordon-bleus, which can avoid resource competition. I recorded the positions and surrounding conditions of the nests and tested if there were species differences. I will also describe some observational findings of nest characteristics in two cordon-bleus.

\section{Methods}

\section{Study site}

This project was conducted under research permits from the Tanzania Wildlife Research Institute (TAWIRI) and the Tanzanian Commission for Science and Technology (COSTECH), permit no. NA-2019-85. I conducted field observations in Mbeya and Iringa region, Tanzania, during the rainy season from March to May 2019, when cordon-bleus usually start pairing and breeding (Goodwin 1982). The recording of the nests was performed while conducting the field observation of courtship display in cordon-bleus (Ota 2020).

\section{Nest observations}

I recorded 43 blue-capped cordon-bleu nests (41 in Mbeya and two in Iringa) and 15 red-cheeked cordon-bleu nests (seven in Mbeya and eight in Iringa). I defined that cordon-bleus were using the nests when bringing or lining nest materials (Movie S1) or staying inside the nest (Fig. 2b). When I found a cordon-bleu nest, I got as close as I could to the nest and recorded its location (longitude and latitude) by BirdLasser, a mobile application to record the observation of birds with the GPS function of the iPhone 7 (Lee \& Nel 2020). There are reports that the GPS accuracy error of the iPhone is in the 7-13 m range (Merry and Bettinger 2019). It may not be suitable for detecting the exact nest locations, but I concluded that it is practical enough to grasp the rough distribution of nesting sites for this study.

I checked the following conditions of the nests: whether the nest owners are blue-capped or red-cheeked cordon-bleus (Fig. 1), if a wasp nest was found nearby on the same tree, and if cordon-bleus built the nest themselves or used weaver nest (Fig. 2). Using these data, I examined species differences in the nesting strategy between blue-capped and red-cheeked cordon-bleus.

I also collected the plant types of nesting sites and the height of the nest from the ground to test if there are any position preferences for nesting in two cordon-bleus. Both cordon-bleus usually nested onAcacia spp. or Acacia -like trees (Faidherbia albida), those are thorny trees with fern-like leaves and are dominant in their habitat. They also nested on shrubs or broadleaf trees as described in the literature (Goodwin 1982). I recorded the types of nested plants into the following three categories: (1)Acacia (-like) trees, (2) shrubs, and (3) broadleaf trees. I also measured the height above the ground of 26 blue-capped nests and 13 red-cheeked nests. Missing values in the nest height are due to that I decided to measure the height from the middle of fieldwork. Therefore it is not related to any external constraints (e.g., too high) around the nest site for the measuring.

Additionally, I sampled a total of five cordon-bleu nests that were no longer used by cordon-bleus to observe the structures and components of their nests. I considered the nests abandoned because I observed neither nest-building nor incubating behavior for more than two weeks after I recorded the locations of the nests. 
I sampled two own-built nests of blue-capped cordon-bleus, one weaver nest used by blue-capped cordonbleus, and two own-built nests of red-cheeked cordon-bleus (Fig. 5). I took the photos and observed the appearances. I also checked the nest components by arbitrarily pulling out some of the nest materials (Fig. $5)$.

\section{Statistical analyses}

Fisher's exact test was used to test the species differences in the use of wasp nests and weaver nests. Chisquare test was used to examine if the proportion of nested plant types vary between cordon-bleus. Student's t-test was used to test the species differences of the nest heights. All statistical analyses and the visualization of figure 3 were performed using R 3.4.4 (R core team 2018). I used the ggplot2 (Wickham 2016) and ggmap (Kahle and Wickham 2013) packages for the distribution map (Fig. 3). All data used in this analyzes are provided in the supplementary information (Appendix S1).

\section{Results}

\section{Nest site selection}

There was a significant species difference in whether a wasp nest was found near the nest (Fisher's exact test, $\mathrm{p}<0.001$, Fig. 4a). Nests were built near a wasp nest more often in red-cheeked cordon-bleus $(80 \%, 12$ of 15 nests) than in blue-capped cordon-bleus (4.7\%, two of 43 nests). Blue-capped cordon-bleus tended to use weaver nests $(23.3 \%, 10$ of 43 nests) more often than red-cheeked cordon-bleus (6.7\%, one of 15 nests), although it was not statistically significant (Fisher's exact test, $\mathrm{p}=0.257$; Fig. $4 \mathrm{~b}$ ). The only weaver nest used by the red-cheeked cordon-bleus was accompanied by a wasp nest (Fig. 2c).

As far as I observed, there seemed to be no clear difference between the two cordon-bleus in their preference for nesting sites - the distribution of nest locations overlapped between the two species (Fig. 3). Further, there were no significant species differences in the types of nested plants and the height of the nest positions. Both species mainly nested on the Acacia / Acacia -like trees (> 80\%; 39 of 43 nests in blue-capped, 13 of 15 nests in red-cheeked) and occasionally on other shrubs (two of 43 nests in blue-capped, zero of 15 nests in red-cheeked) and broad-leaved trees (two of 43 nests in blue-capped, two of 15 nests in red-cheeked). There was no significant difference in the proportion (Chi-square test: $\chi^{2}=1.933, \mathrm{df}=2, \mathrm{p}=0.3803$ ). The height of the nest position was also not significantly different between species (blue-capped: median $\pm \mathrm{SD}=$ $255.5 \pm 72.8 \mathrm{~cm}$, red-cheeked: $250 \pm 72.0 \mathrm{~cm}$; Student's t-test: $\mathrm{t}=0.119, \mathrm{p}=0.906)$.

\section{Nest structures}

Blue-capped cordon-bleus used flowers and their stems of Mollugo nudicaulis and grasses on the outside of the nest (Fig. 2a; Fig. 5a, c). As far as I checked the appearance of the active nest, I never observed that redcheeked cordon-bleus used flowers and their stems on the outside of the nest (Fig. 5a, c-e). The domed nest seemed to be interlaced relatively looser in red-cheeked cordon-bleus than in blue-capped cordon-bleus (Fig. 2a, d; Fig. 5a, c-e), which was in accordance with past descriptions (Hockey et al. 2005, van Someren 1956). The inside was lined with fine grasses and several bird feathers (Fig. 2b, Fig. 5). Even when cordon-bleus used old weaver nests, they added fine grasses inside (Fig. 2b, Fig. 5c, Movie S1).

\section{Discussion}

Contrary to past literature that described the two cordon-bleu species as having nearly the same nesting behavior (Goodwin 1982), my observations revealed that two cordon-bleus adopted different nesting strategies. It seemed one of the factors to enable them to breed sympatrically. The species difference against nesting near a wasp nest likely reflects the difference in their choosiness or order of priority for nest-site selection. Because wasps are generally assumed to build their nests earlier than cordon-bleus (i.e., wasp nests require a longer time to build; Beier and Tungbani 2006, van Someren 1956), and both cordon-bleus built nests at similar positions in the same season. Although my preliminary observations are not conclusive to explain why and how they maintain the niche partitioning, it raises new research questions regarding nesting behavior and highlights the importance of natural history recordings in Estrildid finches. 
A past study of red-cheeked cordon-bleus has shown that nesting near a wasp nest decreases predation risk and contributes to increasing reproductive success (Beier and Tungbani 2006). If nesting near a wasp nest is advantageous for their breeding, it is puzzling why blue-capped cordon-bleus can inhabit sympatrically without a wasp nest. One likely reason is that blue-capped cordon-bleus may compensate for reproductive success by adopting other strategies. Using old weaver nests might contribute to saving the energy of parents for nest building. Throughout my fieldwork, I observed that blue-capped cordon-bleus but not red-cheeked used flowers and their stems of Mollugo nudicaulisand grasses on the outside of the nest (Fig. 2a; Fig. 5a, c). These may increase the robustness and safety of the nest and contribute to a better natal environment for chicks. Alternatively, using wasp nests may not contribute as much to reproductive success for red-cheeked cordon-bleus in areas sympatrically habit with blue-capped cordon-bleus, while may be effective in areas dominated by red-cheeked cordon-bleus (Beier and Tungbani 2006). In order to test these, it is required to investigate the functions of the use of weaver nests and various nest materials. Testing if there are species differences in reproductive success is necessary too. It should also be noted that my finding might be areaspecific rather than species-specific. Environmental differences cause the inter-and intra-species variation in the nest material choice, choosiness, and behavioral plasticity (e.g., Okano et al. 2011). It would be interesting to examine if the nesting strategies vary in different regions with different environmental conditions and populations.

My finding of species difference in nesting strategy implies that there are still overlooked systems and features in the natural history of Estrildidae that we consider well understood. Accumulating natural history knowledge is critical for ecological and behavioral fields because it can tell us not only how we should interpret the results of laboratory experiments but also which research question to ask (Travis 2020). Since Estrildid finches are easy to keep and breed in captivity, studies of their nest-building and its neural mechanisms have been conducted in the laboratory (Guillette and Healy 2015). Well-controlled experiments in captivity have revealed many interesting facts such as the roles of experience, social conditions, and cognitive abilities on nest-building (Bailey et al. 2014, Guillette and Healy 2015, Hall et al. 2015). Those are hard to test in the field. However, collecting the information of the wild behavior is still beneficial and required to expand our idea of the evolutionary background of nest-building behavior. Only a few studies empirically tested how and why wild Estrildid finches build nests under wild conditions (Schuetz 2005, Beier and Tungbani 2006). Furthermore, understanding the nesting strategies of wild Estrildids may also give us a hint to elucidate the evolution of their courtship behavior, in which laboratory experiments have accumulated copious amounts of information. Some Estrildid finches including cordon-bleus are known to hold a piece of nest materials in the beak as a courtship component during song and dance (Ota et al. 2015, Ota 2020), which is presumably derived from nest-building behavior (Soma 2018). It remains unclear how and why they choose the nest materials during courtship, especially from the viewpoint of ecological plausibility. Examining ecological contexts that shape nesting behavior of wild Estrildid finches would give us a new picture of the wide range of behavioral mechanisms and functions.

\section{Acknowledgements}

I am grateful to M. Gahr, W. Goymann, I. Safari, and N. Baker for providing valuable information and advice about conducting fieldwork in Tanzania. I also thank L. Mlawila and N. Gerhard for helping with my fieldwork. The research was financially supported by the National Geographic Society (grant number: EC-KOR-44731R-18), the Kawai Foundation for Sound Technology \& Music, and the Japan Society for the Promotion of Science (JSPS Overseas Research Fellowships).

\section{Competing Interests Statement}

I declare I have no competing interests.

\section{Data Accessibility Statement}

The data are available in the supporting information (Appendix S1).

\section{Literature cited}


Bailey, I. E., Morgan, K. V., Bertin, M., Meddle, S. L., \& Healy, S. D. (2014). Physical cognition: birds learn the structural efficacy of nest material. Proceedings of the Royal Society B: Biological Sciences, 281(1784), 20133225.

Beier, P., \& Tungbani, A. I. (2006). Nesting with the waspRopalidia cincta increases nest success of redcheeked cordonbleu (Uraeginthus bengalus ) in Ghana. The Auk, 123(4), 1022-1037.

Billerman, S. M., Keeney, B. K., Rodewald, P. G., \& Schulenberg, T. S. (2020). Birds of the world. Cornell Laboratory of Ornithology, Ithaca, USA. https://birdsoftheworld.org/bow/homeAccessed May 2021

Catchpole, C. K., \& Slater, P. J. (2003). Bird song: biological themes and variations. Cambridge university press, Cambridge, UK.

Goodwin, D. (1982). Estrildid finches of the world. Cornell University Press, Ithaca, USA.

Guillette, L. M., \& Healy, S. D. (2015). Nest building, the forgotten behaviour. Current opinion in behavioral sciences, 6, 90-96.

Hall, Z. J., Healy, S. D., \& Meddle, S. L. (2015). A role for nonapeptides and dopamine in nest-building behaviour. Journal of Neuroendocrinology, 27(2), 158-165.

Hasui, E., Gomes, V. S. D. M., Kiefer, M. C., Tamashiro, J., \& Silva, W. R. (2009). Spatial and seasonal variation in niche partitioning between blue manakin (Chiroxiphia caudata) and greenish schiffornis (Schiffornis virescens ) in southeastern Brazil. Studies on Neotropical Fauna and Environment, 44(3), 149-159.

Hockey, P. A. R., Dean, W. R. J., and Ryan, P. G. (2005). Roberts' birds of Southern Africa (7th edn). John Voelcker Bird Book Fund, Cape Town, South Africa.

Kahle D., and Wickham, H. (2013). ggmap: spatial visualization with ggplot2. The R Journal, 5(1), 144-161. http://journal.r-project.org/archive/2013-1/kahle-wickham.pdf

Kosinski, Z., \& Winiecki, A. (2004). Nest-site selection and niche partitioning among the Great Spotted Woodpecker Dendrocopos majorand Middle Spotted Woodpecker Dendrocopos medius in riverine forest of Central Europe. Ornis Fennica, 81(4), 145-156.

Lee, A. T. K., \& Nel, H. (2020). BirdLasser: The influence of a mobile app on a citizen science project. African Zoology, 55(2), 155-160.

Levine, J. M., \& HilleRisLambers, J. (2009). The importance of niches for the maintenance of species diversity. Nature, 461(7261), 254-257.

Merry, K., \& Bettinger, P. (2019). Smartphone GPS accuracy study in an urban environment. PloS one, 14(7), e0219890.

Okano, J. I., Kikuchi, E., Sasaki, O., \& Ohi, S. (2011). Geological variation in particle surface-roughness preference in the case-bearing caddisflies. Behavioral Ecology, 22(5), 1053-1063.

Ota, N. (2020). Tap dancers in the wild: field observations of multimodal courtship displays in socially monogamous songbirds. The Science of Nature, 107(4), 30.

Ota, N., Gahr, M., \& Soma, M. (2015). Tap dancing birds: the multimodal mutual courtship display of males and females in a socially monogamous songbird. Scientific reports, 5(1), 16614.

R Core Team. (2018). R: a language and environment for statistical computing. R Foundation for Statistical Computing, Vienna, Austria. https://www.R-project.org/

Schuetz, J. G. (2005). Common waxbills use carnivore scat to reduce the risk of nest predation. Behavioral Ecology, 16(1), 133-137.

Soma, M., \& Garamszegi, L. Z. (2015). Evolution of courtship display in Estrildid finches: dance in relation to female song and plumage ornamentation. Frontiers in Ecology and Evolution, 3, 4. 
Soma, M. (2018). Sexual selection in Estrildid finches, with further review of the evolution of nesting material holding display in relation to cooperative parental nesting. Japanese Journal of Animal Psychology, $68,121-130$.

Travis, J. (2020). Where is natural history in ecological, evolutionary, and behavioral science?. The American Naturalist, 196(1), 1-8.

van Someren, V. G. L. (1956). Days with birds: studies of habits of some East African species. Zoology 38, $1-520$.

Vierling, K. T., Gentry, D. J., \& Haines, A. M. (2009). Nest niche partitioning of Lewis's and Red-headed woodpeckers in burned pine forests. The Wilson Journal of Ornithology, 121(1), 89-96.

Wickham, H. (2016). ggplot2: Elegant graphics for data analysis. Springer International Publishing. Cham, Switzerland.

Figure legends

Figure 1.

(a) A male (left) and a female (right) of blue-capped cordon-bleus Uraeginthus cyanocephalus perching on weaver nests. (b) A male (left) and a female (right) of red-cheeked cordon-bleus Uraeginthus bengalus .

\section{Figure 2.}

Nests owned by blue-capped (a, b) and red-cheeked (c, d) cordon-bleus. (a) The nest built by blue-capped cordon-bleus was located at the upper part of an Acacia tree (yellow circle on the left photo), and there was a wasp nest (pink circle on the right photo) right next to it. The outside of the nest was roughly covered with the flowers and stems of Mollugo nudicaulis (the right photo, see also Fig. 5). (b) The weaver nest was lined with fine grasses brought by blue-capped cordon-bleus, and a male blue-capped cordon-bleu stayed inside (enlarged photo below right). (c) Red-cheeked cordon-bleus used the weaver nest, and there was a wasp nest below it (pink circle). (d) The nest (yellow circle) was built by red-cheeked cordon-bleus in an Acacia tree, accompanied by a wasp nest (pink circle and enlarged photo below).

\section{Figure 3.}

(a) The map of Tanzania and the enlarged map indicates four study sites in Mbeya $(1,2)$ and Iringa $(3,4)$ regions. (b) The distributions of cordon-bleu nests in the four study sites. The nests of blue-capped and red-cheeked cordon-bleus are colored blue and red, respectively. Triangles indicate a wasp nest was found near the nest and circles not.

\section{Figure 4.}

The bars indicate the proportions of (a) nests with (dark red) and without (pink) a wasp nest, and (b) own-built nests (dark green) and weaver nests (light green). An asterisk indicates a statistically significant difference $(\mathrm{p}<0.05)$ between species and N.S. non-significant.

\section{Figure 5.}

(a-e) The photos of nests (left column) and the nest materials (right column). The species and sampled place are shown on the left bars. In addition to grasses, bird feathers were found inside the nests (pink circles) in both blue-capped and red-cheeked cordon-bleus (b-e). Fine grasses and feathers were also found in a weaver nest (b, see also Movie S1). Flowers and stems of Mollugo nudicaulis (blue circles) were found on the outside of the nests only in blue-capped cordon-bleu own built nests (a, c; see also Fig. 2a). 
(a)

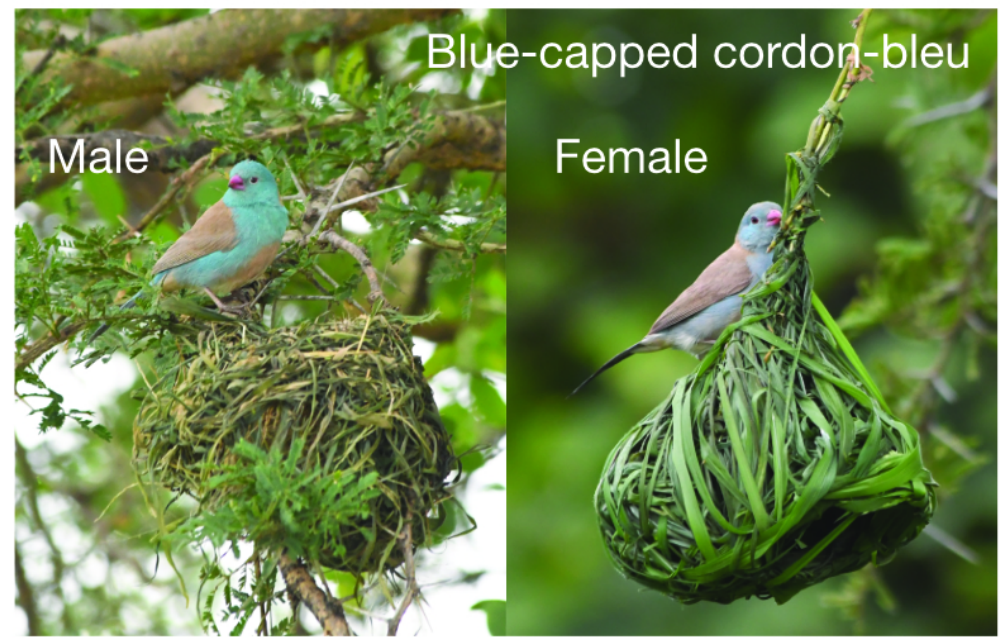

(b)

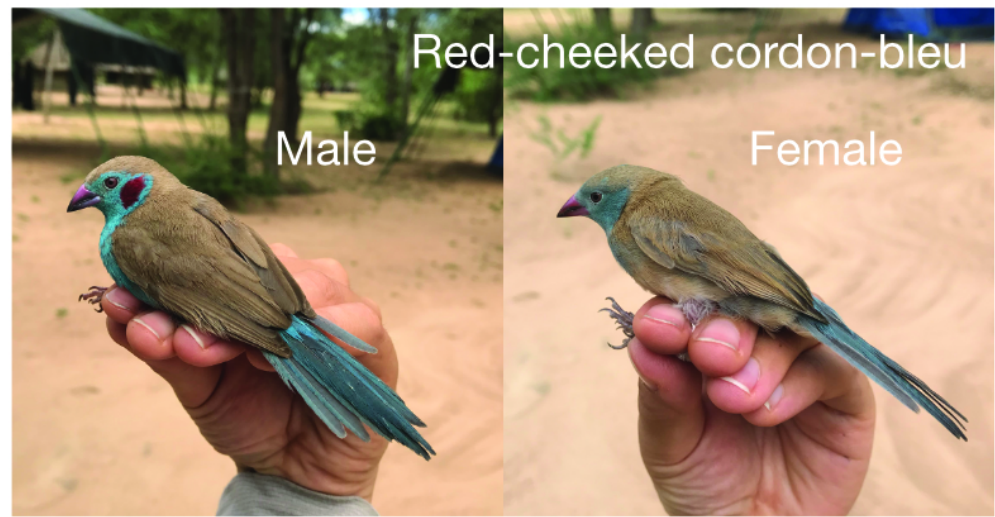



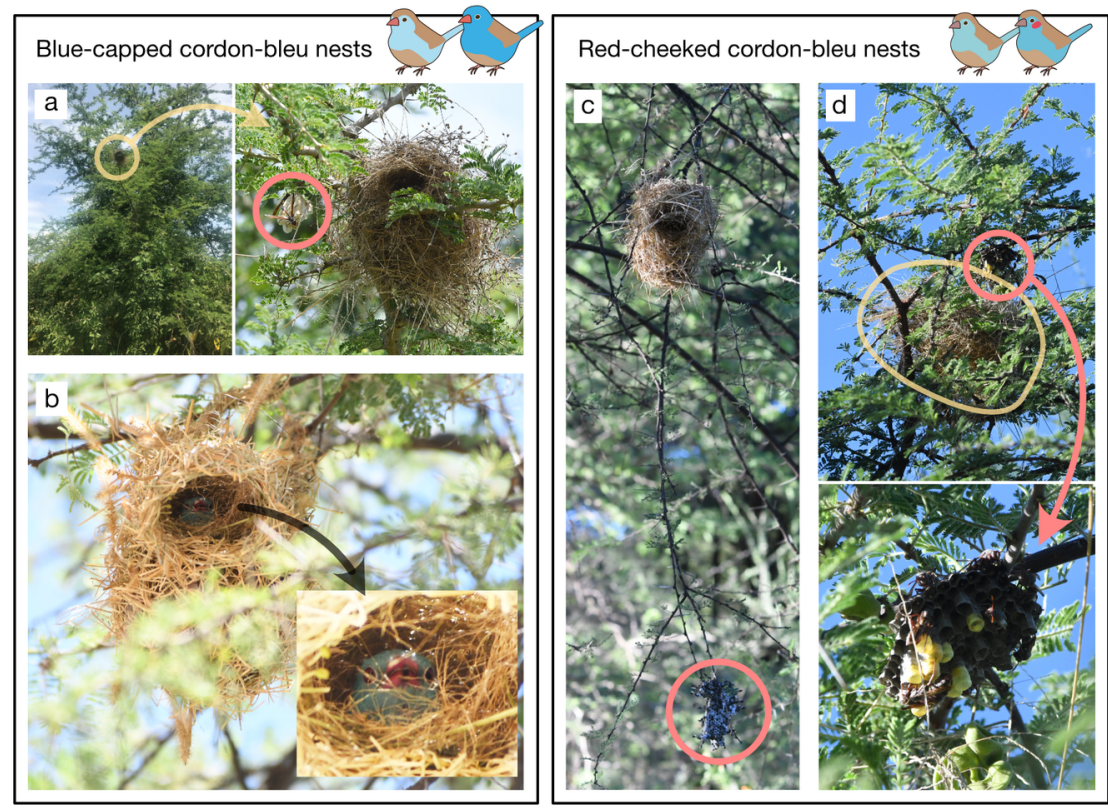

(a)

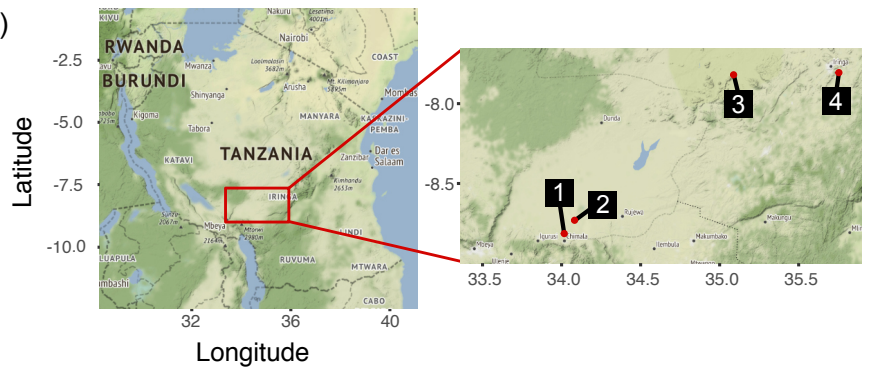

(b)
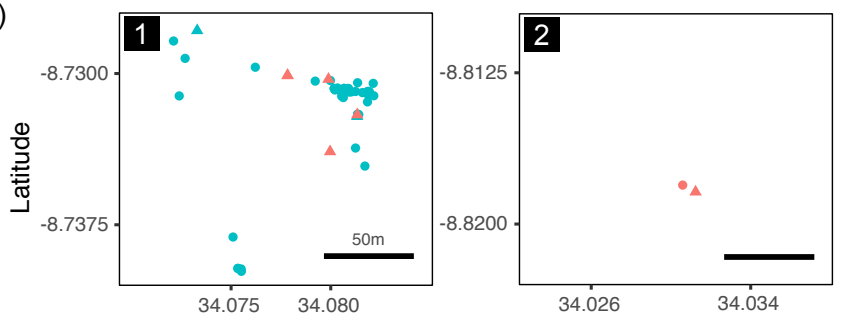

Species

- Blue-capped

Wasp nest

\begin{tabular}{|l|l|}
\hline$\Delta$ & Yes \\
\cline { 1 - 1 } & No \\
\cline { 1 - 1 }
\end{tabular}
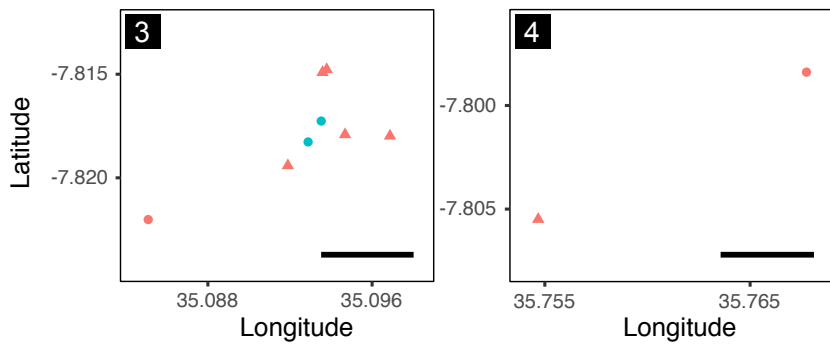
(a)

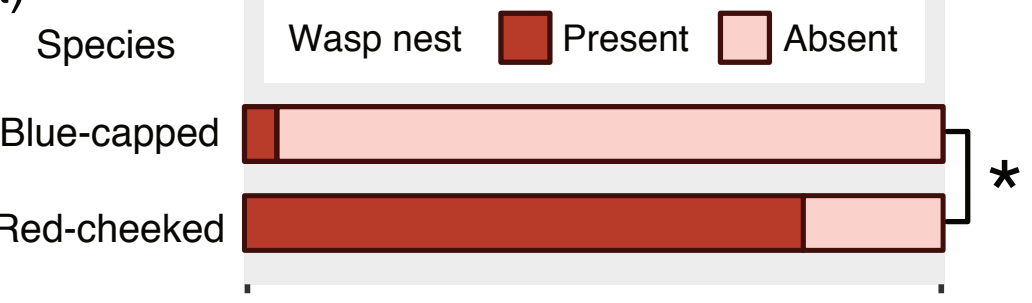

(b)

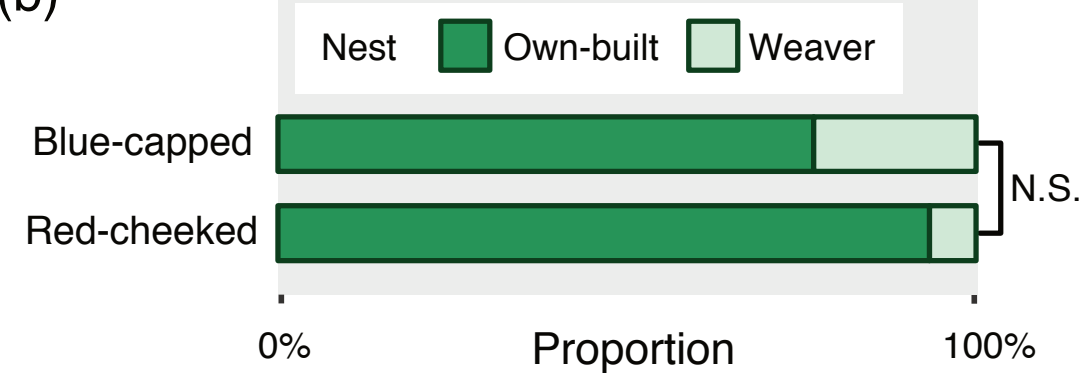




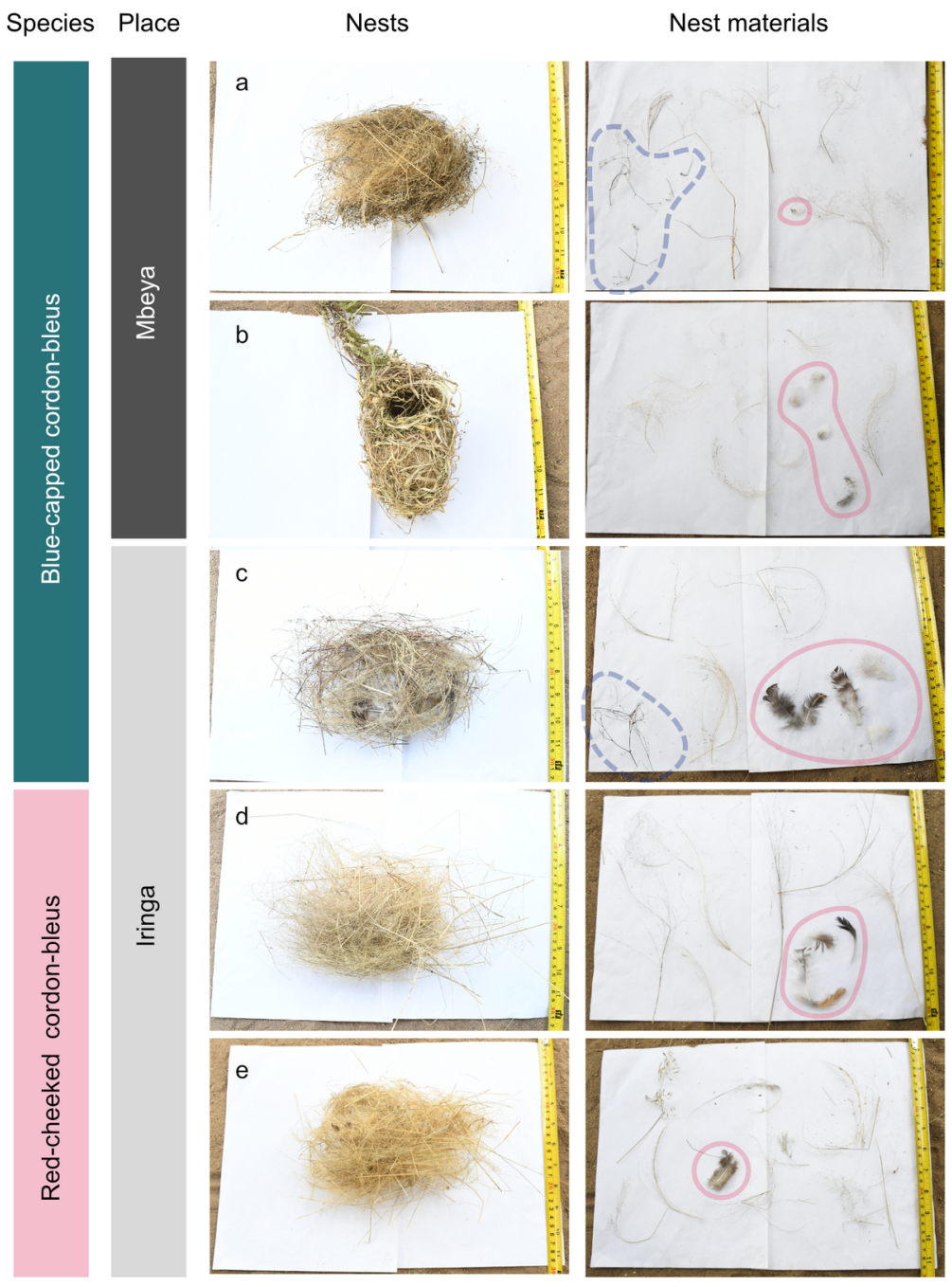




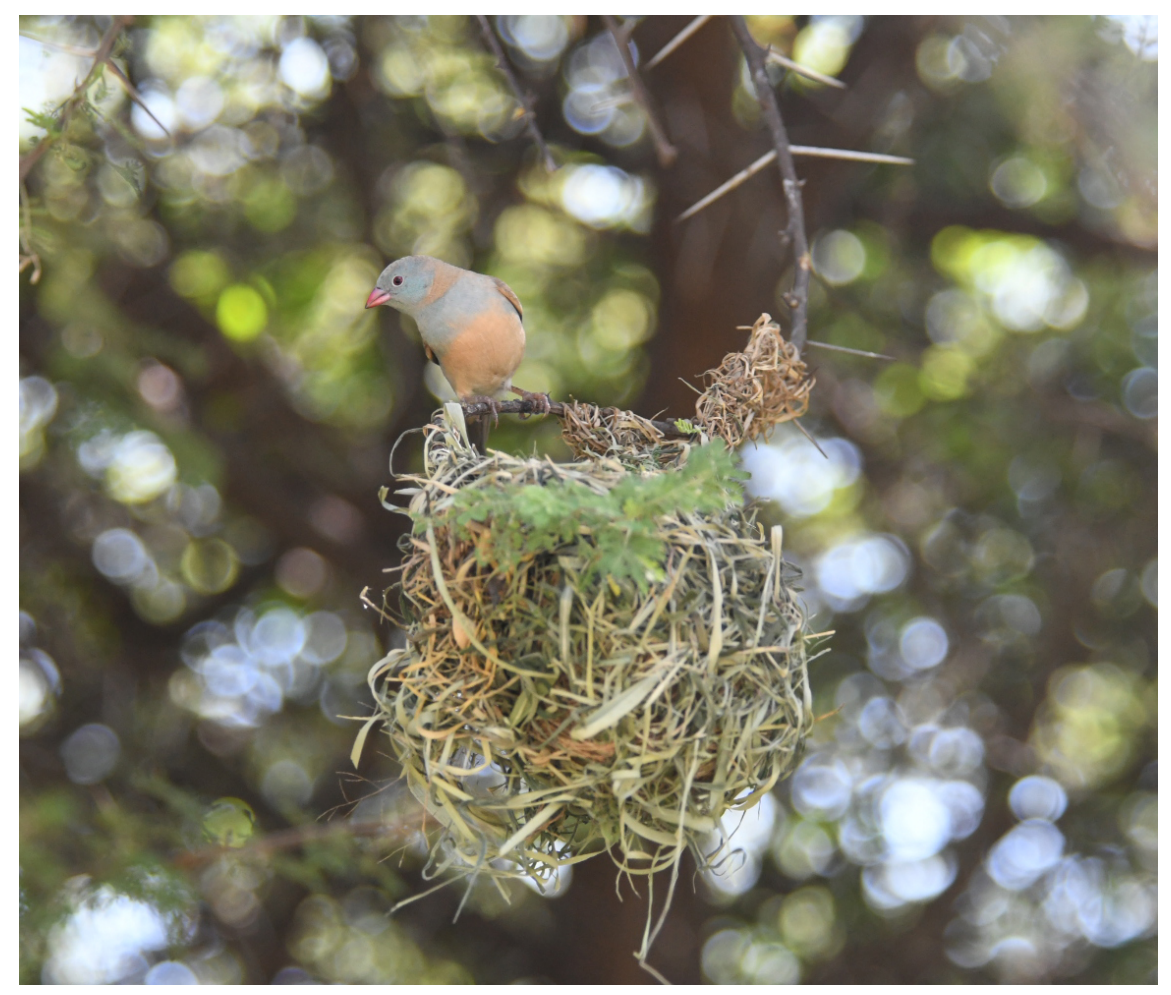

